\title{
ARTICLE Incidence of White Striping and Its Effect on the Quality Traits of Raw and Processed Turkey Breast Meat
}

\author{
Samer Mudalal ${ }^{*}$ \\ Department of Nutrition and Food Technology, Faculty of Agriculture and \\ Veterinary Medicine, An-Najah National University, P.O. Box 7, Nablus, Palestine
}

I OPEN ACCESS

\section{Received March 3, 2019 \\ Revised April 12, 2019 \\ Accepted April 15, 2019}

Abstract The aim of this study is to evaluate the incidence of white striping abnormality and its consequences on the quality traits of raw and processed turkey breast (chemical composition, color traits, and water holding capacity). In total, about 2300 breasts from 22 flocks were used to assess the incidence and 60 breasts to evaluate the quality traits. Our study showed that the total incidence of moderate and severe white striping was $61.3 \%$ out of them, moderate cases were $49.4 \%$. Severe white striped turkey breast exhibited significantly lower protein content $(21.1$ vs. 23.2 and $23.16 \%, p<0.05)$ and higher fat content $(2.3$ vs. 0.77 and $1.76 \%, p<0.05)$ if compared to normal and moderate white striped breast respectively. Moreover, moderate and severe white striped meat showed significantly higher redness $\left(\mathrm{a}^{*}\right)(2.98$ and 3.14 vs. $1.48, \mathrm{p}<0.05)$ and yellowness $\left(b^{*}\right)$ indexes ( 7.27 and 7.95 vs. $\left.4.05, p<0.05\right)$ than normal meat, respectively.

Keywords white striping, turkey, breast, quality, incidence

\section{Introduction}

Huge efforts in genetic selections have been exerted in the last decades to optimize the growth of poultry broilers. In addition, genetic selection has led to improvements in fat reduction, breast size, and feed conversion (Barbut et al., 2008). Accordingly, some current hybrid birds exhibited breast yield more than $20 \%$ if compared with pure breeds (Havenstein et al., 2003). Chicken and turkey breast meat have functional characteristics such as their contents of bioactive peptides, long-chain n-3 polyunsaturated fatty acids (PUFA), conjugated linoleic acid (CLA), vitamins and antioxidants (Gibbs et al., 2010; Ryan et al., 2011). Moreover, it is well known that breast meat has low fat content. On the contrary, recent studies showed that the nutritional profile of chicken meat was not similar as in the past. In this context, currently produced chicken meat is characterized with high fat content if compared with that produced some years ago (Crawford et al., 2010; Wang et al., 2009).

(C) Korean Society for Food Science of Animal Resources. This is an open access article distributed under the terms of the Creative Commons Attribution Non-Commercial License (http://creativecommons.org/licences/by-nc/3.0) which permits unrestricted non-commercial use, distribution, and reproduction in any medium, provided the original work is properly cited. 
Several studies showed that the incidence of muscle abnormalities increased as a consequence of intensive genetic selections to optimize the growth of broilers (Dransfield and Sosnicki, 1999; Mahon, 1999). In this context, the most familiar muscle abnormalities in poultry sector are: deep pectoral muscle disease (Bianchi et al., 2006) and PSE-like meat (pale, soft, and exudative-like condition). Recent muscle abnormalities have also been observed such as white striping (Bauermeister et al., 2009; Kuttappan et al., 2009) and wooden breast (Sihvo et al., 2014). Pectoralis major muscle containing white striations in parallel to muscle fibers was defined as white striping abnormality (Kuttappan et al., 2009).

The effect of several farming factors on incidence of white striping have been evaluated by previous studies. Petracci et al. (2013) studied the effect of genotypes (high and standard breast yield hybrids) on the incidence of white striping and it was found that high breast hybrids exhibited higher incidence of white striping than standard breast yield hybrids. Kuttappan et al. (2013b) found that male birds exhibited higher incidence of white striping than female birds. The same authors also found that high energy diet increased the incidence more than low energy diet. Kuttappan et al. (2012b) found that the incidence of white striping reached to $50 \%$ while the estimation of white striping incidence was $12 \%$ by Petracci et al. (2013). Even the etiological origin of white striping is still unknown, but several authors showed that white striping abnormality was companied by different histological lesions such as disappearance of cross striations, differences in fiber size, fibers degeneration/regeneration, fibrosis and lipidosis, and signs of inflammation (Kuttappan et al., 2013a; Shivo et al., 2014).

Most of previous studies were focused to evaluate the incidence of white striping and its consequences on the quality traits of chicken breast meat from different genotypes reared under different farming factors. The available knowledge about the effect of white striping on turkey breast meat is very limited. Therefore, the aim of this study is to evaluate the incidence of white striping in turkey breast as well as it is effect on the quality traits of raw and processed meat products.

\section{Materials and Methods}

\section{Evaluation of the prevalence of white striping}

The prevalence of white striping was carried out in Palestinian slaughterhouse near Tulkarm city (Palestine) during the period of May to September 2018. About 2,300 turkey breasts (from 20-week old tom turkey birds) were randomly collected from 22 flocks. The incidence of white striping was evaluated on the processing line after deboning by $16-18 \mathrm{~h}$. From each flocks about 100 breast muscles were selected to evaluate the incidence of white striping. The classification of white striping was based on the presence and thickness of white striations on the cranial area of breast where breast scored as severe case when the white striations thickness is more than $1 \mathrm{~mm}$ and moderate case when the thickness of white striations is less than 1 $\mathrm{mm}$. Normal breast was scored when there is no any whole white striations on the cranial area (Kuttappan et al., 2012c).

\section{Samples selection for quality analysis}

To evaluate the effect of white striping on the quality traits of raw and processed turkey breast, 60 the pectoralis major muscles of 20-week old tom turkey birds were randomly selected based on the appearance of white striations from local Palestinian slaughterhouse near Tulkarm city (Palestine). The same previously mentioned approach to classify the degree of white striping was followed. The samples were classified into three groups ( $\mathrm{n}=12 /$ group): normal, moderate, and severe. The experiment was carried out in two replicates.

\section{Analysis of quality traits of raw breast meat}

Color traits $\left(\mathrm{CIE} \mathrm{L}^{*}=\right.$ lightness, $\mathrm{a}^{*}=$ redness and $\mathrm{b}^{*}=$ yellowness $)$ were assessed in triplicate by the using a Chroma Meter 
CR-410 (Konica Minolta, Japan) considering the skin-side surface of each fillet from cranial area. For each raw fillet, proximate composition (moisture, protein, ash and lipid contents) has been determined according to the official methods of AOAC (1990). For $\mathrm{pH}$, it was measured by using method described by Jeacocke (1977). To determine the thawing loss, a parallel rectangles meat sample $(60 \times 40 \times 20 \mathrm{~mm})$ were removed from the cranial area and stored at $-18^{\circ} \mathrm{C}$ for two months then the samples were defrosted on plastic strain overnight in refrigerator at $4^{\circ} \mathrm{C}$. The difference in weights before and after defrosting has been recorded to determine thawing loss.

\section{Analysis of quality traits of marinated breast meat}

From each breast, a cut $(10 \times 5 \times 3 \mathrm{~cm})$ has been excised from the cranial area to evaluate purge loss, marinade uptake, yield and cooking loss. All meat samples from three groups were marinated and tumbled by using a small- scale vacuum tumbler (MGH-20, Vakona Qualitat, Lienen, Germany) for $25 \mathrm{~min}$ (speed $20 \mathrm{rpm}, 500$ rounds) at pressure of 0.95 bars.

The marinade solution containing $7.5 \%$ of sodium chloride and $2 \%$ sodium tripolyphosphate (STPP) were used to achieve $1.5 \%$ and $0.4 \%$ for sodium chloride and sodium tripolyphosphate (STPP) in finished product after marination, respectively. The weight of meat samples was measured after marination to determine marinade uptake, the samples were stored in refrigerator at $2^{\circ} \mathrm{C}$ to $4^{\circ} \mathrm{C}$ for $48 \mathrm{~h}$, and then the samples were weighted to calculate purge loss. After $48 \mathrm{~h}$, samples were vacuum-packed and cooked in water bath at $80^{\circ} \mathrm{C}$ for 24 min until the core temperature arrived $80^{\circ} \mathrm{C}$. After the samples has been cooled to room temperature, they were removed from bags and reweighed to measure cook loss, as well as total yield based on weight before marination.

\section{Statistical analysis}

The effect of different levels of white striping (normal, moderate, and severe) on the quality traits of turkey breast was evaluated by ANOVA. General linear model (GLM) model was used to test the main effects of WS levels (normal, moderate, or severe) and replication, as well as the interaction term using the (SAS, 1988) on meat quality traits. Means were separated using Duncan test with $\mathrm{p}<0.05$ considered as significant.

\section{Results and Discussion}

The incidence of white striping is shown in Fig. 1. It was found that total incidence was $61.3 \%$ including moderate and severe white striping. In particular, the incidence of moderate white striping was $49.4 \%$ while the incidence of severe cases was $11.9 \%$. In this context, there are no available studies about the incidence of white striping abnormality in turkey breast but there were several studies evaluated the incidence of white striping in chicken breasts. In this context, Lorenzi et al. (2014) found that the total incidence of white striping was $43 \%$ in chicken breast meat from different breeds chicken. Kuttappan et al. (2012b) found that the total incidence of white striping in chicken breast was $50.7 \%$ (out of them 36.7 moderate and 14\% severe cases). In 2013, the same authors observed that the total incidence of WS was 55.8\%. Moreover, Russo et al. (2015) found that medium and heavy-weight broilers exhibited overall prevalence of WS $70.2 \%$ and $82.51 \%$ respectively. In general, the occurrence rates of white striping in chicken breast were associated by different factors such as age, sex, body weight, growth rate, and genotype (Kuttappan et al., 2012a; Kuttappan et al., 2012b). Further studies are needed to evaluate the effect of previous factors on the incidence of white striping in turkey breast.

The results of quality parameters (thawing loss, $\mathrm{pH}, \mathrm{a}^{*}, \mathrm{~b}^{*}, \mathrm{~L}^{*}$, and calories content) and proximate chemical composition 


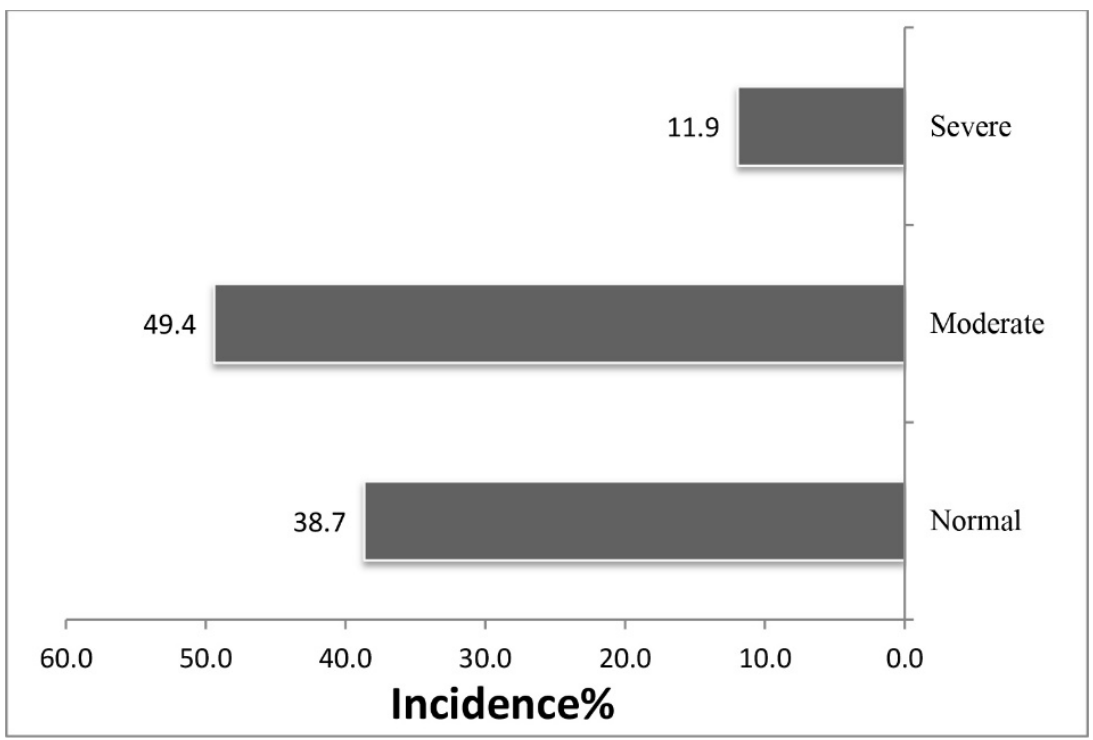

Fig. 1. The incidence of white striping in turkey breast meat classified as normal, moderate, and severe where the levels of white striping was classified according to Kuttappan et al. (2012c).

(moisture content, protein content, fat content, and ash content) of raw turkey breast meat are shown in Table 1. Our finding showed that the presence of white striping defects changed some chemical properties of breast meat. In this context, severe white striped turkey breast exhibited significantly lower protein contents ( 21.08 vs. 23.17 and $23.16 \%$, p $<0.05)$ and higher fat contents $(2.25$ vs. 0.77 and $1.47 \%, \mathrm{p}<0.05)$ if compared to normal and moderate white striped breast respectively. The low content of proteins can be attributed to degeneration of muscle fibers which have been observed in histological evaluation from previous studies (Shivo et al., 2014). Moreover, several researchers observed that myodegeneration was companied by fibrosis and adiposis which may explain the high fat content (Kuttappan et al., 2009; Shivo et al., 2014). On another hand,

Table 1. Physical (thawing loss, $\mathrm{pH}, \mathrm{L}^{*}, \mathrm{a}^{*}, \mathrm{~b}^{*}$, and calories content) and chemical (moisture content, protein content, fat content, and ash content) characteristics of raw turkey breast meat

\begin{tabular}{|c|c|c|c|c|}
\hline \multirow{2}{*}{ Quality parameters } & \multicolumn{3}{|c|}{ Level of white striping ${ }^{1)}$} & \multirow{2}{*}{$\mathrm{p}$} \\
\hline & Normal & Moderate & Severe & \\
\hline \multicolumn{5}{|l|}{ Color indexes } \\
\hline $\mathrm{L}_{\mathrm{r}}$ & $66.60 \pm 2.50$ & $64.11 \pm 4.30$ & $64.39 \pm 3.97$ & 0.67 \\
\hline$a^{*}$ & $1.48 \pm 1.15$ & $2.98 \pm 1.62$ & $3.14 \pm 1.46$ & $<0.05$ \\
\hline$b *_{r}$ & $4.08 \pm 1.70^{\mathrm{b}}$ & $7.27 \pm 2.89^{\mathrm{a}}$ & $7.95 \pm 1.86^{\mathrm{a}}$ & $<0.05$ \\
\hline $\mathrm{pH}$ & $6.10 \pm 0.09^{\mathrm{b}}$ & $6.16 \pm 0.06^{\mathrm{a}}$ & $6.20 \pm 0.06^{\mathrm{a}}$ & $<0.05$ \\
\hline Moisture (\%) & $75.48 \pm 1.15$ & $76.07 \pm 1.55$ & $75.52 \pm 1.19$ & 0.53 \\
\hline Protein $(\%)$ & $23.17 \pm 2.01^{\mathrm{a}}$ & $23.16 \pm 1.46^{\mathrm{a}}$ & $21.08 \pm 1.67^{b}$ & $<0.05$ \\
\hline Fat $(\%)$ & $0.77 \pm 0.51^{\mathrm{b}}$ & $1.47 \pm 1.67^{\mathrm{ab}}$ & $2.25 \pm 1.14^{\mathrm{a}}$ & $<0.05$ \\
\hline Ash (\%) & $2.25 \pm 1.31$ & $1.73 \pm 0.42$ & $1.57 \pm 0.25$ & 0.18 \\
\hline Calories & $130.00 \pm 10.38$ & $122.61 \pm 10.01$ & $128.61 \pm 6.47$ & 0.30 \\
\hline Freeze loss & $2.27 \pm 0.47$ & $1.88 \pm 0.33$ & $2.05 \pm 0.54$ & 0.18 \\
\hline
\end{tabular}

1) The levels of white striping were classified into normal, moderate and severe according to Kuttappan et al. (2012c).

${ }^{a, b}$ Means within a row followed by different superscript letters differ significantly $(p<0.05)$. 
there were no significant differences in moisture, ash, and calories contents between groups. Moderate and severe white striped meat had pH significantly higher $(6.16$ and 6.20 vs. 6.10, $\mathrm{p}<0.5)$ than normal meat, respectively. Tijare et al. (2016) and Mudalal et al. (2014) found similar results where white striped meat had higher $\mathrm{pH}$ than normal meat. It was found that white striping defect had significant impact on color traits. Moderate and severe white striped meat showed significantly higher redness $\left(\mathrm{a}^{*}\right)(2.98$ and 3.14 vs. $1.48, \mathrm{p}<0.05)$ and yellowness $\left(\mathrm{b}^{*}\right)$ indexes $(7.27$ and 7.95 vs. $4.08, \mathrm{p}<0.05)$ than normal meat, respectively. Similar findings have been observed in chicken breast meat from several researchers (Mudalal et al., 2014; Sihvo et al., 2014). The high values of redness $\left(\mathrm{a}^{*}\right)$ and yellowness $\left(\mathrm{b}^{*}\right)$ were seen in chicken breast meat in previous studies and were explained due to high pH values and high fat content, respectively (Petracci et al., 2014; Sihvo et al., 2014; Tijare et al., 2016). There were no significant differences in lightness ( $\left.\mathrm{L}^{*}\right)$ between groups but all values of lightness were in range of Pale Soft Exudate breast meat ( $\left.\mathrm{L}^{*}>53\right)$. For freezing loss, there were no significant differences between groups.

Quality parameters of marinated (marinade up take, drip loss and, $\mathrm{L}^{*}, \mathrm{a}^{*}, \mathrm{~b}^{*}$ ) and cooked (cooking loss, yield, and color indexes) turkey breast meat are shown in Table 2. After marination, there were no significant differences in color indexes. Similarly, cooked breast meat did not show any significant differences in $\mathrm{L}^{*}$ and $\mathrm{b}^{*}$ values. Moderate and severe white striped cooked breast had higher $\mathrm{b}^{*}$-values $(13.75$ and 13.04 vs. $11.92, \mathrm{p}<0.05)$ than normal meat. This result can be attributed due to high fat content. The presence of white striping had no effect on marinade uptake, drip loss, cooking loss, and yield. These results were partially in agreement with previous studies (Bauermeister et al., 2009; Kuttappan et al., 2009).

The effect of processing (raw, marination, and cooking) on the color traits $\left(\mathrm{L}^{*}, \mathrm{a}^{*}\right.$, and $\mathrm{b}^{*}$ ) of normal, moderate, and severe white striping turkey breast meat was shown in Table 3. In general, marination and cooking did no exhibit any significant effect on redness index $\left(\mathrm{a}^{*}\right)$ for normal, moderate, and severe white striping meat. Lightness $\left(\mathrm{L}^{*}\right)$ significantly decreased after marination (66.60 vs. 58.56, p<0.05; Normal, 64.11 vs. 59.28, $\mathrm{p}<0.05$; moderate, and 64.39 vs. 61.16 , p $<0.05$; severe) and increased after cooking (66.60 vs. $88.28, \mathrm{p}<0.05$; Normal, 88.53 vs. $64.11, \mathrm{p}<0.05$; moderate, and 88.61 vs. 61.16,

Table 2. Quality parameters of marinated (marinade up take, drip loss, L*, a*, and b*) and cooked (cooking loss, yield, and color indexes) turkey breast meat

\begin{tabular}{|c|c|c|c|c|}
\hline \multirow{2}{*}{ Quality parameters } & \multicolumn{3}{|c|}{ Level of white striping ${ }^{1)}$} & \multirow{2}{*}{$\mathrm{p}$} \\
\hline & Normal & Moderate & Severe & \\
\hline \multicolumn{5}{|l|}{ Color indexes } \\
\hline $\mathrm{L}^{*} \mathrm{~m}$ & $58.55 \pm 2.62$ & $59.28 \pm 2.51$ & $61.16 \pm 3.45$ & 0.10 \\
\hline$a *_{m}$ & $2.10 \pm 0.93$ & $2.84 \pm 1.50$ & $3.30 \pm 1.65$ & 0.25 \\
\hline $\mathrm{b}^{*} \mathrm{~m}$ & $2.95 \pm 2.01$ & $3.98 \pm 2.45$ & $5.10 \pm 1.75$ & 0.07 \\
\hline \multicolumn{5}{|l|}{ Color indexes } \\
\hline $\mathrm{L} * \mathrm{c}$ & $89.27 \pm 2.83$ & $88.53 \pm 3.39$ & $88.60 \pm 3.25$ & 0.82 \\
\hline$a^{*}{ }_{c}$ & $2.69 \pm 0.85$ & $2.88 \pm 1.22$ & $2.91 \pm 1.41$ & 0.88 \\
\hline $\mathrm{b}^{*} \mathrm{c}$ & $11.92 \pm 0.94^{\mathrm{b}}$ & $13.75 \pm 0.82^{\mathrm{a}}$ & $13.04 \pm 1.65^{\mathrm{a}}$ & $<0.05$ \\
\hline Marinade uptake & $15.93 \pm 3.63$ & $15.56 \pm 3.41$ & $13.74 \pm 2.39$ & 0.56 \\
\hline Drip loss $(\%)$ & $7.51 \pm 1.38$ & $6.35 \pm 2.84$ & $6.78 \pm 1.26$ & 0.76 \\
\hline Cooking loss (\%) & $18.65 \pm 1.78$ & $17.96 \pm 1.51$ & $18.35 \pm 2.51$ & 0.56 \\
\hline Yield (\%) & $94.36 \pm 3.00$ & $95.10 \pm 2.36$ & $92.96 \pm 3.81$ & 0.26 \\
\hline
\end{tabular}

1) The levels of white striping were classified into normal, moderate and severe according to Kuttappan et al. (2012c).

${ }^{\mathrm{a}, \mathrm{b}}$ Means within a row followed by different superscript letters differ significantly $(\mathrm{p}<0.05)$. 
Table 3. Color traits $\left(\mathrm{L}^{*}, \mathrm{a}^{*}\right.$, and $\left.\mathrm{b}^{*}\right)$ of raw, marinated, and cooked turkey breast affected by different levels of white striping

\begin{tabular}{|c|c|c|c|c|}
\hline \multirow{2}{*}{ Quality parameters } & \multicolumn{3}{|c|}{ Level of white striping ${ }^{1)}$} & \multirow{2}{*}{$\mathrm{p}$} \\
\hline & Raw & Marinated & Cooked & \\
\hline \multicolumn{5}{|l|}{ Normal } \\
\hline \multicolumn{5}{|l|}{ Color indexes } \\
\hline $\mathrm{L}^{*}$ & $66.60 \pm 2.50^{\mathrm{b}}$ & $58.55 \pm 2.62^{\mathrm{c}}$ & $89.27 \pm 2.83^{\mathrm{a}}$ & $<0.05$ \\
\hline$a^{*}$ & $1.48 \pm 1.15$ & $2.10 \pm 0.93$ & $2.69 \pm 0.85$ & 0.53 \\
\hline$b^{*}$ & $4.08 \pm 1.70^{\mathrm{b}}$ & $2.95 \pm 2.01^{\mathrm{c}}$ & $11.92 \pm 0.94^{\mathrm{a}}$ & $<0.05$ \\
\hline \multicolumn{5}{|l|}{ Moderate } \\
\hline \multicolumn{5}{|l|}{ Color indexes } \\
\hline $\mathrm{L}^{*}$ & $64.11 \pm 4.30^{\mathrm{b}}$ & $59.28 \pm 2.51^{\mathrm{c}}$ & $88.53 \pm 3.39^{\mathrm{a}}$ & $<0.05$ \\
\hline $\mathrm{a}^{*}$ & $2.98 \pm 1.62$ & $2.84 \pm 1.50$ & $2.88 \pm 1.22$ & 0.89 \\
\hline$b^{*}$ & $7.27 \pm 2.89^{\mathrm{b}}$ & $3.98 \pm 2.45^{\mathrm{c}}$ & $13.75 \pm 0.82^{\mathrm{a}}$ & $<0.05$ \\
\hline \multicolumn{5}{|l|}{ Severe } \\
\hline \multicolumn{5}{|l|}{ Color indexes } \\
\hline $\mathrm{L}^{*}$ & $64.39 \pm 3.97^{\mathrm{b}}$ & $61.16 \pm 3.45^{\mathrm{c}}$ & $88.60 \pm 3.25^{\mathrm{a}}$ & $<0.05$ \\
\hline$a^{*}$ & $3.14 \pm 1.46$ & $3.30 \pm 1.65$ & $2.91 \pm 1.41$ & 0.89 \\
\hline$b^{*}$ & $7.95 \pm 1.86^{\mathrm{b}}$ & $5.10 \pm 1.75^{\mathrm{c}}$ & $13.04 \pm 1.65^{\mathrm{a}}$ & $<0.05$ \\
\hline
\end{tabular}

1) The levels of white striping were classified into normal, moderate and severe according to Kuttappan et al. (2012c).

${ }^{\mathrm{a}-\mathrm{c}}$ Means within a row followed by different superscript letters differ significantly $(\mathrm{p}<0.05)$.

$\mathrm{p}<0.05$; severe) for all groups respectively. For all groups, breast meat exhibited significantly lower values of yellowness ( $\left.\mathrm{b}^{*}\right)$ after marination ( 4.08 vs. 2.95 , normal; 7.27 vs. 3.98 , moderate; 7.95 vs. 5.10 , severe) if compared with raw meat.

After cooking, yellowness index ( $\left.b^{*}\right)$ increased significantly (11.92 vs. 4.08, normal; 13.75 vs. 7.27, moderate; 13.04 vs. 7.95 , severe) in all groups. Generally, there were no agreement on the effect of marination and cooking on color indexes between previous studies. Young et al. (2005) did not find differences in color indexes after marination except for $b^{*}$ values in marinated fillets were lower when compared to non-marinated fillets. It was found that marinated poultry muscles exhibited lower red $\left(\mathrm{a}^{*}\right)$ and yellow ( $\left.\mathrm{b}^{*}\right)$ values when compared to non-marinated meat (Lyon et al., 1998). In another study, there was slight significant decrease after marination in $\mathrm{L}^{*}$ and $\mathrm{a}^{*}$ values (Smith and Young, 2007). Some previous studies showed that both $\mathrm{a}^{*}$ and $\mathrm{b}^{*}$ values decreased in marinated fillets (Young and Lyon, 1997; Allen et al., 1998).

The marinated cooked samples exhibited lighter (higher $\mathrm{L}^{*}$ ) and more yellow (higher $\mathrm{b}^{*}$ ) whereas $\mathrm{a}^{*}$ (red color) increased as temperature and cooking time increased (Resurreccion, 2004). The high values of lightness $\left(\mathrm{L}^{*}\right)$ values after cooking may be explained due to increase in light scattering and reflection as result of fiber shrinkage after cooking (Alvarado and Sams, 2003).

In conclusion, the prevalence of white striping in turkey breast was relatively high. Moreover, white striping abnormality had adversely affect some of the quality traits of turkey breast meat which was more characterized with high fat and low protein contents as well as different color indexes ( $\mathrm{a}^{*}$ and $\left.\mathrm{b}^{*}\right)$.

\section{Conflicts of Interest}

The authors declare no potential conflict of interest. 


\section{Acknowledgments}

This work has been financed from the Deanship of Scientific Research at An-Najah National University under project number ANNU-MoHE-1819-Sc012 and ANNU-1718-Sc022.

\section{Author Contributions}

The article is prepared by a single author.

\section{Ethics Approval}

This article does not require IRB/IACUC approval because there are no human and animal participants.

\section{References}

Allen CD, Fletcher DL, Northcutt JK, Russell SM. 1998. The relationship of broiler breast color to meat quality and shelflife. Poult Sci 77:361-366.

Alvarado CZ, Sams AR. 2003. Injection marination strategies for remediation of pale, exudative broiler breast meat. Poult Sci 82:1332-1336.

Barbut S, Sosnicki AA, Lonergan SM, Knapp T, Ciobanu DC, Gatcliffe LJ, Huff Lonergan E, Wilson EW. 2008. Progress in reducing the pale, soft and exudative (PSE) problem in pork and poultry meat. Meat Sci 79:46-63.

Bauermeister LJ, Morey AU, Moran ET, Singh M, Owens CM, McKee SR. 2009. Occurrence of white striping in chicken breast fillets in relation to broiler size. Poult Sci 88:33.

Bianchi M, Petracci M, Franchini A, Cavani C. 2006. The occurrence of deep pectoral myopathy in roaster chickens. Poult Sci 85:1843-1846.

Crawford MA, Wang Y, Lehane C, Ghebremeskel K. 2010. Fatty acid ratios in free-living and domestic animals. In Modern dietary fat intakes in disease promotion. De Meester F, Zibadi S, Waston RR (ed). Humana Press Inc., New York, NY, USA. pp 95-108.

Dransfield E, Sosnicki AA. 1999. Relationship between muscle growth and poultry meat quality. Poult Sci 78:743-746.

Gibbs RA, Rymer C, Givens DI. 2010. Postgraduate symposium: Long-chain n-3 PUFA: intakes in the UK and the potential of a chicken meat prototype to increase them. Conference on 'Over and undernutrition: challenges and approaches'. Proc Nutr Soc 69:144-155.

Havenstein GB, Ferket PR, Qureshi MA. 2003. Growth, livability, and feed conversion of 1957 versus 2001 broilers when fed representative 1957 and 2001 broiler diets. Poult Sci 82:1500-1508.

Jeacocke RE. 1977. Continuous measurements of the $\mathrm{pH}$ of beef muscle in intact beef carcases. Int J Food Sci Technol 12:375-386.

Kuttappan VA, Brewer VB, Apple JK, Waldroup PW, Owens CM. 2012b. Influence of growth rate on the occurrence of white striping in broiler breast fillets. Poult Sci 91:2677-2685.

Kuttappan VA, Brewer VB, Clark FD, McKee SR, Meullenet JF, Emmert JL, Owens CM. 2009. Effect of white striping on the histological and meat quality characteristics of broiler fillets. Poult Sci 88:136-137.

Kuttappan VA, Brewer VB, Mauromoustakos A, McKee SR, Emmert JL, Meullenet JF, Owens CM. 2013b. Estimation of 
factors associated with the occurrence of white striping in broiler breast fillets. Poult Sci 92:811-819.

Kuttappan VA, Goodgame SD, Bradley CD, Mauromoustakos A, Hargis BM, Waldroup PW, Owens CM. 2012a. Effect of different levels of dietary vitamin E (DL- $\alpha$ tocopherol acetate) on the occurrence of various degrees of white striping on broiler breast fillets. Poult Sci 91:3230-3235.

Kuttappan VA, Lee YS, Erf GF, Meullenet JFC, McKee SR, Owens CM. 2012c. Consumer acceptance of visual appearance of broiler breast meat with varying degrees of white striping. Poult Sci 91:1240-1247.

Kuttappan VA, Shivaprasad HL, Shaw DP, Valentine BA, Hargis BM, Clark FD, McKee SR, Owens CM. $2013 \mathrm{a}$. Pathological changes associated with white striping in broiler breast muscles. Poult Sci 92:331-338.

Lorenzi M, Mudalal S, Cavani C, Petracci M. 2014. Incidence of white striping under commercial conditions in medium and heavy broiler chickens. J Appl Poult Res 23:754-758.

Lyon CE, Lyon BG, Dickens JA. 1998. Effects of carcass stimulation, deboning time, and marination on color and texture of broiler breast meat. J Appl Poult Res 7:53-60.

Mahon M. 1999. Muscle abnormalities-morphological aspects. In Poultry meat science. Richardson RI, Mead GC (ed). CABI Publishing, Oxon, UK. pp 19-64.

Mudalal S, Lorenzi M, Soglia F, Cavani C, Petracci M. 2014. Implications of white striping and wooden breast abnormalities on quality traits of raw and marinated chicken meat. Animal 9:728-734.

Petracci M, Mudalal S, Babini E, Cavani C. 2014. Effect of white striping on chemical composition and nutritional value of chicken breast meat. Ital J Anim Sci 13:179-183.

Petracci M, Mudalal S, Bonfiglio A, Cavani C. 2013. Occurrence of white striping under commercial conditions and its impact on breast meat quality in broiler chickens. Poult Sci 92:1670-1675.

Resurreccion AVA. 2004. Sensory aspects of consumer choices for meat and meat products. Meat Sci 66:11-20.

Russo E, Drigo M, Longoni C, Pezzotti R, Fasoli P, Recordati C. 2015. Evaluation of white striping prevalence and predisposing factors in broilers at slaughter. Poult Sci 94:1843-1848.

Ryan JT, Ross RP, Bolton D, Fitzgerald GF, Stanton C. 2011. Bioactive peptides from muscle sources: meat and fish. Nutrients 3:765-791.

SAS. 1988. SAS/STAT Guide for personal computers, Version 6.03 edition. SAS Institute Inc., Cary, NC, USA.

Sihvo HK, Immonen K, Puolanne E. 2014. Myodegeneration with fibrosis and regeneration in the pectoralis major muscle of broilers. Vet Pathol 51:619-623.

Siller WG. 1985. Deep pectoral myopathy: A penalty of succesful selection for muscle growth. Poult Sci 64:1591-1595.

Smith DP, Young LL. 2007. Marination pressure and phosphate effects on broiler breast fillet yield, tenderness, and color. Poult Sci 86:2666-2670.

Tijare VV, Yang FL, Kuttappan VA, Alvarado CZ, Coon CN, Owens CM. 2016. Meat quality of broiler breast fillets with white striping and woody breast muscle myopathies. Poult Sci 95:2167-2173.

Wang Y, Lehane C, Ghebremeski K, Crawford MA. 2009. Modern organic and broiler chickens sold for human consumption provide more energy from fat than protein. Public Health Nutr 13:400-408.

Young LL, Cason J, Smith DP, Lyon CE, Dickens JA, Walker JM. 2005. Effects of electrical stimulation and simulated conventional and extended chilling method on cooked chicken breast meat texture and yield. Int J Poult Sci 4:60-63.

Young LL, Lyon CE. 1997. Effect of post-chill aging and sodium tripolyphosphates on moisture binding properties, color, and Warner-Bratzler shear values of chicken breast meat. Poult Sci 76:1587-1590. 